\title{
Adolescent vegetable consumption: the role of socioemotional family characteristics
}

Elisabeth Lind Melbye ${ }^{1,2}$, Solveig Hausken Sutter ${ }^{3}$, Nanna $_{\text {Lien }}^{3} \&$ Mona Bjelland ${ }^{3}$

${ }^{1}$ Norwegian School of Hotel Management, Faculty of Social Sciences, University of Stavanger, P.O. Box 8600, FORUS, 4036 Stavanger, Norway.

${ }^{2}$ Oral Health Center of Expertise, Public Dental Health Care in Rogaland, P.O. Box 130, Sentrum, 4001 Stavanger, Norway.

${ }^{3}$ Department of Nutrition, Institute of Basic Medical Sciences, Faculty of Medicine, University of Oslo, P.O. Box 1046, Blindern, NO-0316, Oslo, Norway.

Corresponding author: Elisabeth Lind Melbye, e-mail address:

elisabeth.lind.melbye@throg.no, telephone: +47 51506844

Short title: Family processes and vegetable consumption

Acknowledgements: The authors would like to thank participating schools, students and staff participating in data collection.

Financial Support: The present work is part of The Family \& Dietary habits project, which was funded by the Norwegian Research Council [grant number 213857/H10].

\section{Conflict of Interest: None.}

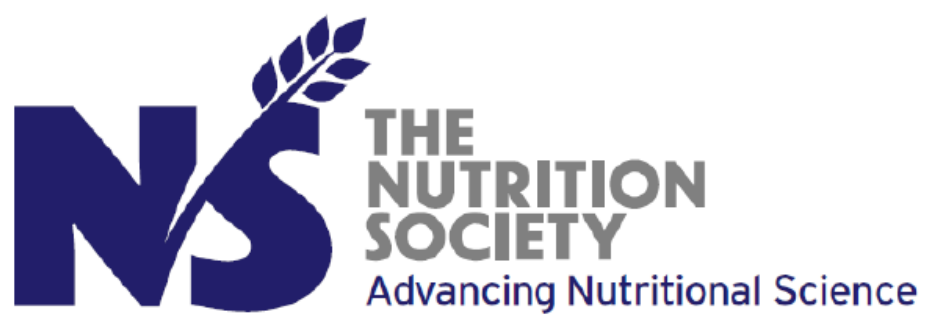

This is an Accepted Manuscript for Public Health Nutrition as part of the Cambridge Coronavirus Collection. This peer-reviewed article has been accepted for publication but not yet copyedited or typeset, and so may be subject to change during the production process.

The article is considered published and may be $\mathrm{c}$ ited using its DOI $10.1017 /$ S 1368980021001658

Public Health Nutrition is published by Cambridge University Press on behalf of The Nutrition Society 
Authorship: All authors participated in the development of the study framework and measurement instruments. MB and NL designed the study. MB and SHS collected the data. ELM performed statistical analyses and drafted the manuscript. All authors provided critical revision of the paper and approved the final manuscript.

Ethical Standards Disclosure: This study was conducted according to the guidelines laid down in the Declaration of Helsinki and all procedures involving research study participants were approved by the Norwegian Social Sciences Data Services. The Regional Committee for Medical and Health Research Ethics was also informed, but no approval was needed. Since the subjects were underaged, written informed consent was obtained from all subjects and their parents. 
Accepted manuscript

\title{
Adolescent vegetable consumption: the role of socioemotional family characteristics
}

\begin{abstract}
Objectives: To describe associations between adolescents' frequency of vegetable consumption, food parenting practices and socioemotional family characteristics, and to explore potential mediated relationships that may contribute to an understanding of the family processes involved.

Design: Cross-sectional survey among adolescents aged 13-15 years.

Setting: A survey questionnaire including self-report measures on adolescents' frequency of vegetable consumption, perceived food parenting practices (i.e. family dinner frequency, maternal/paternal healthy eating guidance, maternal/paternal social support for vegetable consumption) and socioemotional family characteristics (i.e. general family functioning and level of cohesion and conflict within the family) was distributed in a convenience sample of secondary school students.
\end{abstract}

Participants: 440 students from five secondary schools in eastern Norway completed the questionnaire.

Results: Results from multiple linear regression analysis revealed positive and statistically significant associations between adolescents' frequency of vegetable consumption, maternal healthy eating guidance and family cohesion. A partial indirect (mediated) association between family cohesion and adolescents' frequency of vegetable consumption, working through maternal healthy eating guidance, was also found.

Conclusions: Results from the present study suggest that perceived family cohesion may influence adolescents' frequency of vegetable consumption both directly and indirectly. However, there is a need for continued investigation of family-related factors influencing adolescent eating. In particular, the role of socioemotional family characteristics should be further scrutinized in future studies. 
Keywords: vegetable consumption; adolescents; socioemotional family characteristics; family cohesion; food parenting practices; healthy eating guidance 


\section{Introduction}

An insufficient intake of fruit and vegetables (FV) is found to be among the leading risk factors of the global burden of non-communicable diseases ${ }^{(1)}$. Therefore, it is a concern that most adolescents in the Nordic countries and elsewhere have a lower consumption of FV, particularly vegetables, than recommended by the authorities ${ }^{(2-4)}$. Adolescence is known as a critical period for the development of dietary behaviors ${ }^{(5)}$, and since such behaviors are likely to track into adult life ${ }^{(6)}$, it is important to increase FV consumption among adolescents to reduce morbidity and mortality from non-communicable diseases. Thus, continued research aiming to reveal key influences on adolescent FV consumption, and to develop effective interventions tailored at this group of the population, seems imperative.

In Norway, which is the setting of the present study, the Norwegian School Fruit Scheme (NSFS) was launched in 2007 as part of a Norwegian governmental initiative to promote and increase the consumption of FV among children and adolescents. The NSFS provided students in all secondary schools (grades 8-10) and all combined schools (grades 1-10) with a free piece of fruit or vegetable every school day. The program lasted for seven years and resulted in an increased fruit consumption among adolescents regardless of gender and socioeconomic status. However, the same positive effect was not found for vegetables ${ }^{(7-9)}$. One obvious reason is that the program primarily delivered fruits to the students. Thus, the potential for increasing vegetable consumption through the NSFS was limited.

Correspondingly, a review by Evans, Cristian, Cleghorn et al. ${ }^{(10)}$ found that school-based interventions moderately improved fruit intake but had minimal impact on vegetable intake.

The influence of the traditional Norwegian meal pattern, which typically includes one hot meal (dinner) and two or three cold meals ${ }^{(11)}$ must be taken into consideration in the assessment of Norwegian adolescents' vegetable consumption. The cold meals usually consist of bread or cereals. Fruit is more practical to eat with these cold meals and in between meals than vegetables, as they come in convenient portion sizes, 'in their own package' and need little treatment prior to eating compared to vegetables ${ }^{(12)}$. Consequently, in Norway, vegetables are mostly eaten at dinner ${ }^{(13)}$, which most children and adolescents share with their families ${ }^{(14,15)}$. The importance of family meals for more healthful food choices has been stated in reviews by Berge ${ }^{(16)}$ and Fulkerson, Larson, Horning et al. ${ }^{(17)}$, and the presence of at least one parent at meals has been associated with a higher FV consumption ${ }^{(17,18)}$. Moreover, 
irregular family meals (breakfasts and dinners) have been associated with less vegetable consumption in a recent study by Totland, Knudsen, Paulsen et al. ${ }^{(19)}$. Hence, a relevant approach for understanding predictors of adolescents' vegetable consumption might be recognizing family-related factors, besides shared family dinners, that could influence this behavior.

Since the family environment has been acknowledged as a fundamental context for the development of eating behaviors ${ }^{(20)}$, several studies have addressed factors such as socioeconomic position ${ }^{(2)}$ and various food parenting practices, including the arrangement of family meals ${ }^{(21-23)}$. However, less research has focused on fundamental, socioemotional family characteristics such as general family functioning and level of family cohesion or conflict as correlates of adolescent eating ${ }^{(24)}$. Previous research has linked socioemotional family characteristics to social and emotional outcomes in youth ${ }^{(25-27)}$, and Kitzmann \& Beech ${ }^{(28)}$ have accentuated the importance of exploring these fundamental family characteristics in relation to (un)healthy eating among adolescents. Moreover, these features of the family environment have been suggested as contexts that may enhance or limit the effectiveness of family-based interventions ${ }^{(28,29)}$. Thus, it seems relevant to scrutinize the role of socioemotional family characteristics as potential determinants of adolescent vegetable consumption.

The present study is part of the Family and Dietary Habits (F\&D) project, and is based on a framework constructed to describe various family environmental levels and constructs included in questionnaires developed for this project ${ }^{(30)}$. The F\&D framework constitutes an ecological model emphasizing factors within the family environment that may contribute to explain dietary behaviors in adolescents. The factors included in this framework are organized in three levels: an individual level (adolescent eating and personal characteristics), a parental level (parenting style and food parenting practices, including parents' arrangement of shared family meals) and a family level (fundamental socioemotional family characteristics), with factors interacting within and across levels. Adolescent vegetable consumption was the individual level factor of interest in the present study and served as the dependent variable in model analyses. Parental level factors hypothesized to be related to adolescent vegetable consumption were food parenting practices such as family dinner frequency, healthy eating guidance and positive encouragement for vegetable consumption. Family level factors hypothesized to be related to adolescent vegetable consumption were fundamental 
socioemotional family characteristics such as general family functioning, family cohesion and family conflict.

Based on this introductory section, the objectives of the present study were to: 1) describe associations between adolescent vegetable consumption and the parental- and family level factors presented above, and 2) explore potential mediated relationships that may contribute to an increased understanding of the family processes involved.

\section{Methods}

\section{Participants and procedures}

Secondary school students aged 13-15 years were recruited through a convenience sample of five public schools in eastern Norway. Since the students were underaged, a parental consent form including questions assessing household educational level was distributed to the students' parents. After receiving written consent from parents, students who agreed to participate were asked to complete a web-based questionnaire during school hours. Of the 1136 students invited to take part in this cross-sectional study, 440 (39\%) completed the questionnaire.

\section{Questionnaire}

The students spent between 25-45 minutes on completing the questionnaire, which consisted of 141 questions assessing dietary intake (vegetables and sugar-sweetened beverages (SSB)), accessibility and availability (of vegetables and SSB), personal characteristics, family meals, parenting styles, food parenting practices, socioemotional family characteristics, and sociodemographic factors ${ }^{(30)}$. All measures in the questionnaire, including parental and family level factors, were assessed from the perspective of the students. The subset of measures used in the current study is presented in the following paragraphs.

\section{Frequency of vegetable consumption}

Vegetable consumption was assessed using frequency measures reproduced from Lien, Bjelland, Bergh et al. ${ }^{(31)}$. Students were asked two questions to report their usual intake of cold (raw) and heated (boiled, fried, roasted, etc.) vegetables, respectively, on an 8-point frequency scale $(1=$ never/seldom, $2=$ less than once a week, $3=1-2$ times a week, $4=3-4$ times a week, 5 =5-6 times a week, $6=$ once a day, $7=2$ times a day, $8=3$ times a day or 
more). Vegetable juices were not included in this measure. As suggested by Andersen, Bere, Kolbjørnsen et al. ${ }^{(32)}$, the response categories were recoded to reflect vegetable consumption in times per week prior to data analyses $(0=$ never/seldom; $0.5=$ less than once a week; $1.5=$ 1-2 times a week; $3.5=3-4$ times a week; 5.5 = 5-6 times a week; $7=$ once a day; $14=$ twice a day; 21 = 3 times a day). Consequently, all response categories had a common denominator (times a week), which improved the readability of the results and increased comparability with studies using similar measures ${ }^{(31-34)}$. Total frequency of vegetable consumption was calculated by adding up the consumption of cold and heated vegetables.

\section{Family dinner frequency}

Family dinner frequency was measured with one item: 'How often does your mother and/or father usually sit down and eat dinner with you?'. Response alternatives were given on an 8point frequency scale $(1=$ never/seldom; $2=$ once a week; $3=$ twice a week; $4=3$ times a week; $5=4$ times a week; $6=5$ times a week; $7=6$ times a week; $8=7$ times a week). This variable was not normally distributed as most of the adolescents ate dinner together with their parent(s) 6 or 7 times per week (80.5\%). Therefore, responses were dichotomized into ' $0-5$ times a week' and '6-7 times a week'.

\section{Healthy eating guidance}

The concept of healthy eating guidance (HEG) was developed by Haszard, Williams, Dawson et al. ${ }^{(35)}$ and includes food parenting practices like teaching about nutrition, modeling healthy eating, encouraging a balanced and varied diet and making healthy foods and beverages accessible in the home. In the present study, perceived maternal and paternal HEG was measured separately for mothers and fathers by the 9-item HEG subscale adapted from Haszard, Williams, Dawson et al.'s ${ }^{(35)} 5$-factor version of Musher-Eizenman \& Holub's (36) Comprehensive Feeding Practices Questionnaire (CFPQ). To the authors' knowledge, the CFPQ has previously been used to assess food parenting practices from a parental perspective only. Thus, the items had to be slightly modified to represent the perspective of adolescents in the current research. E.g., 'My mother/father discusses with me why it is important to eat healthy foods' (see Appendix 1 for a complete list of HEG items). The HEG items were scored on a 5-point Likert scale ranging from 1 (disagree) to 5 (agree), where the sum of scores was divided by 9 to give a total average score ranging from 1.0 to 5.0. Higher scores indicate higher levels of HEG. Haszard, Williams, Dawson et al. ${ }^{(35)}$ reported good internal consistency reliability for the HEG subscale with an alpha coefficient of 0.82 . Also construct 
validity was supported by Haszard, Williams, Dawson et al. ${ }^{(35)}$, as parents with concern for child overweight, and parents who rated a healthy diet as very important for their child, were found to report higher levels of HEG. Previous testing of the CFPQ with parents in a Norwegian setting indicated that this instrument is also a valid tool for measuring multiple parental feeding practices with parents of 10-12 year-olds ${ }^{(37)}$.

\section{Positive encouragement for vegetable consumption}

Parents' encouragement of healthy eating behaviors has been associated with positive outcomes ${ }^{(38)}$. For example, Melbye, $\emptyset$ gaard \& $\emptyset_{\text {verby }}{ }^{(39)}$ found a positive association between parental encouragement of a balanced and varied diet and vegetable intake in 10-12year-olds. Furthermore, Young, Fors \& Hayes ${ }^{(40)}$ found that perceived parental support for FV consumption was a significant predictor of FV consumption in adolescents. In the current research, perceived maternal and paternal positive encouragement was measured by the 5item Positive Encouragement Subscale (PES) adapted from Dave, Evans, Condransky et al.'s ${ }^{(38)}$ Emotional Social Support Scale (ESSPS) for FV intake. Since vegetable consumption was the dependent variable of interest in the present study, the PES was modified to cover intake of vegetables only: 'How often, during the past month, did your mother/father 1) compliment you for your vegetable consumption, 2) encourage you to eat vegetables when you were tempted not to, 3) discuss your vegetable consumption with you, 4) remind you to eat vegetables and 5) asked you on ideas on how you could eat more vegetables'. The PES items were scored on a 5-point frequency scale ranging from 1 (never) to 5 (very often), where the sum of scores was divided by 5 to give a total average score ranging from 1.0 to 5.0. Higher scores indicate higher levels of positive encouragement. Dave, Evans, Condransky et al. ${ }^{(38)}$ observed good internal consistency for the PES with an alpha coefficient of 0.82 . They also found evidence of construct validity, as the PES correlated with related measures such as reinforcement, availability and accessibility.

\section{General family functioning}

General family functioning includes structural, organizational and interactional patterns of the family as described by Bowen's ${ }^{(41)}$ Family Systems Theory. According to this theory, the interactions that occur within a family are reciprocal in that each member of the family is being shaped by other family members' behaviors. These mutual influences may provide insight into behaviors that ultimately determine health outcomes in individual family members ${ }^{(24)}$. In the current research, perceived family functioning was measured with the 
General Functioning Scale (GFS), which is a 12-item subscale extracted from the McMaster Family Assessment Device (FAD) ${ }^{(42)}$. E.g., 'Planning family activities is difficult because we misunderstand each other' (see Appendix 1 for a complete list of GFS items). The GFS response categories ranged from 1 (strongly agree) to 4 (strongly disagree), where the sum of scores was divided by 12 to give a total average score ranging from 1.0 to 4.0. A higher score (i.e. $\geq 2.0$ ) indicates poorer family functioning ${ }^{(43,44)}$. The GFS has demonstrated good psychometric properties with adolescents in various cultural contexts ${ }^{(45-47)}$.

\section{Family cohesion and family conflict}

Family cohesion has been defined as the degree of perceived commitment, support and help family members provide for each other, or as the emotional connection between family members ${ }^{(48)}$. Cohesion is recognized as an important influence on children's development and functioning ${ }^{(49,50)}$ and has been shown to affect adolescents' feeling of control over their own health ${ }^{(51)}$. Interestingly, previous studies have suggested a link between family cohesion and healthy dietary behaviors among adolescents ${ }^{(50,52-54)}$. Family conflict has been defined as the degree of perceived aggression and conflict among family members ${ }^{(55)}$, and in contrast to cohesion, it has been associated with negative outcomes in children and adolescents ${ }^{(55-58)}$. For example, in a study by Schuetzmann, Richter-Appelt, Schulte-Markwort et al. ${ }^{(59)}$, conflict and rejection was linked to deviant eating behavior in preadolescents. Furthermore, family conflict has been associated with unhealthy eating in high-school students ${ }^{(54)}$. In the present study, family cohesion and family conflict were measured by items derived from the Cohesion (9 items) and Conflict (8 items) subscales included in the Family Environment Scale (FES) ${ }^{(48)}$. E.g., cohesion: 'Family members really help and support one another'. E.g., conflict: 'We fight a lot in our family' (see Appendix 1 for a complete list of items measuring cohesion and conflict). The cohesion and conflict items were scored on a 4-point scale ranging from 1 (true) to 4 (false). As for other rating scale variables in this study, averaged sum scores for the cohesion and conflict subscales were calculated. Higher scores indicate higher levels of cohesion and conflict respectively ${ }^{(60)}$. Previous research assessing the psychometric properties of the FES, from which the cohesion and conflict scales are derived, have shown inconsistent results. In terms of internal consistency reliability for the FES subscales, the originally reported alpha coefficients varied between 0.64 to 0.79 , with an acceptable benchmark to be above 0.60 (this value was justified by the emphasis placed on the breadth of the measured constructs) ${ }^{(48)}$. In a study by Charalampous, Kokkinos \& Panayiutou ${ }^{(60)}$, where the validity and reliability of the FES were tested with individuals aged 16-60 years, the 
cohesion and conflict scales emerged as unidimensional, supporting the convergent validity of the scales. The alpha coefficients were found to be similar to the alpha coefficients originally reported by Moos \& Moos ${ }^{(48)} ; 0.74$ and 0.64 for cohesion and conflict, respectively. Charalampous, Kokkinos \& Panayiutou ${ }^{(60)}$ endorsed the strong theoretical basis and predictive utility of the scales which make them fruitful for examining the family environment. Furthermore, in a study by Kalavana, Maes \& de Gucht ${ }^{(54)}$, where the FES was administered to senior high-school students (mean age $16.6, \mathrm{SD}=4.8$ ) the construct validity of the cohesion and conflict subscales were supported, and both factors had an acceptable internal consistency with alphas of 0.76 (cohesion) and 0.74 (conflict). The internal consistency for the cohesion and conflict subscales were also found to be acceptable in a more recent study on adolescents aged 11-18, with reported alphas of 0.80 (cohesion) and 0.75 (conflict) ${ }^{(61)}$.

\section{Sociodemographic factors}

Sociodemographic factors are well-known, inflexible correlates of dietary behaviors and were included as covariates in the current study. Data from the parent with the longest education was used as a measure of highest household educational level and was classified as 'less than or equal to 12 years', 'between 13 and 16 years', and 'more than 16 years'. Gender was classified as 'boy' or 'girl'. Family structure was classified as 'living with both parents' vs. 'other living arrangements'.

\section{Statistical analyses}

\section{Initial analyses}

The SPSS statistical software package version 25 (SPSS Inc., Chicago, IL, USA) was used for statistical analyses. Initial analyses included frequencies for categorical variables, and mean scores, standard deviations, skewness, kurtosis, Cronbach's alphas and ICCs for rating scale variables. As suggested by Kline ${ }^{(62)}$, we applied cut-off values of 3.0 and 8.0 for skewness and kurtosis, respectively. Cronbach's alpha was used to assess internal consistency reliability for all rating scale variables and was classified as $>0.70=$ "acceptable" and $>0.80$ $=$ "preferable" (63). Intra-class correlations coefficients (ICC) were used to assess test-retest reliability in a subsample of adolescents $(n=54)$, and were classified as $\geq 0.81$ = "excellent", $0.61-0.80=$ "moderate" and $\leq 0.40=$ "poor" (64). Prior to regression analyses, bivariate correlations were run to test for multicollinearity between independent variables. We applied 
a cut-off value of 0.80 or greater for multicollinearity, as suggested by Haerens, Craeynest, Deforche et al. ${ }^{(53)}$.

\section{Model analyses}

Two different regression strategies were applied to address the research objectives. First, a multiple linear regression analysis was run to describe associations between adolescents' frequency of vegetable consumption (individual level), perceived food parenting practices (parental level) and socioemotional family characteristics (family level) derived from the F\&D framework. Sociodemographic factors were also included and treated as covariates. Next, based on results from the multiple linear regression, potential mediated relationships were explored. The analytical strategy applied to test for mediation was based on Hayes' (65) modeling tool PROCESS, version 3. This tool includes bootstrapping resampling techniques resulting in more robust results than standard methods relying on parametric assumptions ${ }^{(66)}$. Since approximately 5000 bootstrap samples are considered sufficient for most applications ${ }^{(67)}$, and since it is the current PROCESS default, we generated 5000 bootstrap samples for the mediation analysis by resampling with replacement from the original sample. Associations between predictor and mediator, and between mediator and outcome variable, were reported in traditional manner by unstandardized coefficients and associated p-values. This was also the case for total and direct associations between predictor and outcome variable. Since pvalues for indirect (mediated) effects are not displayed in the PROCESS output, the indirect effect was reported by unstandardized regression coefficients with $95 \%$ confidence intervals. Conforming to the bootstrapping approach, an indirect effect which confidence interval did not include zero was considered statistically significant ${ }^{(66)}$.

\section{Results}

\section{Initial analyses}

Frequencies for categorical variables are presented in Table 1. As can be seen from this table, the sample consisted of 52\% girls and $48 \%$ boys. Most adolescents (74\%) came from highly educated households (34\% with 13-16 years of education, 27\% with more than 16 years of education), and a large proportion (69\%) lived together with both parents. Mean scores, standard deviations, skewness, kurtosis, Cronbach's alphas and ICCs for rating scale variables are presented in Table 2. As depicted in this table, all variables had values within the range of chosen cut-offs for skewness and kurtosis, Cronbach's alphas were satisfactory to preferable 
(range: 0.72 - 0.89), and ICCs were good to excellent (range: 0.68 -0.83). Finally, no multicollinearities were found for the independent variables to be included in subsequent model analyses (range: $0.01-0.33$ ).

\section{Model analyses}

The multiple linear regression analysis resulted in positive and statistically significant associations between adolescents' frequency of vegetable consumption and perceived maternal healthy eating guidance $(\beta=0.22, p=0.04)$, family cohesion $(\beta=0.21, p=0.02)$ and household educational level $(\beta=0.11, \mathrm{p}=0.04)$, explaining $9 \%$ of the variance in vegetable consumption (Table 3). Based on these results, a single-mediator model including these variables was tested to explore the potential processes involved.

Since a causal model is the theoretical basis for the examination of potential mediating mechanisms, the temporal order assumption of a causal model was taken into account when specifying this model. To be more specific; in a three-variable mediation model, the independent variable $\mathrm{X}$ is hypothesized to precede (and cause) mediator $\mathrm{M}$, which, in turn, precedes (and causes) dependent variable $\mathrm{Y}$, such that accounting for the effect of $\mathrm{X}$ on $\mathrm{M}$ and of $\mathrm{M}$ on $\mathrm{Y}$ explains, in part or in whole, the influence of $\mathrm{X}$ on $\mathrm{Y}^{(68)}$. Following from this, it seems reasonable that family cohesion (which is a fundamental family characteristic) temporally precedes, and thus may have the potential to influence, adolescents' perceptions, or acknowledgement, of maternal HEG (which is a context specific, food-related behavior). The opposite (perceived maternal HEG influencing family cohesion) seems less likely. Likewise, it seems reasonable that maternal HEG temporally precedes, and may have the potential to influence adolescents' frequency of vegetable consumption. Consequently, family cohesion was included as the predictor (X), while maternal HEG was included as the potential mediator (M) of the association between family cohesion and adolescents' frequency of vegetable consumption (Y). Household educational level was included as a covariate. Results from mediation analysis showed that family cohesion was significantly and positively associated with maternal HEG $(b=0.65, \mathrm{p}<0.001)$ and that maternal HEG was significantly and positively associated with adolescents' frequency of vegetable consumption $(b=0.90, p<$ 0.05). Positive, statistically significant total $(b=2.63, \mathrm{p}<0.001)$ and $\operatorname{direct}(\mathrm{b}=2.04, \mathrm{p}<$ 0.01 ) associations were also found between family cohesion and adolescents' frequency of vegetable consumption. Finally, a statistically significant indirect (mediating) effect of perceived maternal HEG on the association between family cohesion and adolescents' 
frequency of vegetable consumption $(b=0.58, \mathrm{CI}(0.11-1.15)$ was found. This effect accounted for about $22 \%$ of the total effect of family cohesion on adolescent vegetable consumption (i.e. ratio of indirect to total effect, $\mathrm{P}_{\mathrm{M}}=0.22$ ), and thus represents a partial mediation (Figure 1).

\section{Discussion}

The present study aimed to: 1) describe associations between adolescents' frequency of vegetable consumption, selected food parenting practices and socioemotional family characteristics, and 2) explore potential mediated relationships that may contribute to an increased understanding of the family processes involved. Family cohesion and maternal HEG was found to be the most important correlates of vegetable consumption frequency in the multiple linear regression model, while household educational level appeared as a weaker correlate. When testing for mediated relationships (adjusting for household educational level), maternal HEG was found to act as a partial mediator of the positive association between family cohesion and adolescents' frequency of vegetable consumption.

The finding of a positive association between family cohesion and adolescents' frequency of vegetable consumption is supported by previous research by Franko, Thompson, Bauserman, et al. ${ }^{(52)}$, which indicates that family cohesion may be linked to healthy eating in numerous ways: First, a cohesive family may be a family that explicitly promotes healthy behaviors: e.g., parents encourage healthy eating, and adolescents who feel a high level of connectedness with their parents may be more inclined to follow their suggestions. Second, cohesion has been linked to psychological health, which may have a direct effect on the development of healthy attitudes and behaviors (including healthy eating) in children and adolescents ${ }^{(52,53,69)}$.

The positive association between maternal HEG and adolescents' frequency of vegetable consumption is in line with former studies on social influences postulating that the influence of important others are essential elements for explaining child and adolescent eating behaviors. For example, in a cohort study among children aged 6-11 years and their parents Couch, Glanz, Zhou et al. ${ }^{(70)}$ found that food parenting practices such as encouragement, modeling and family rules showed strong positive relationships with child FV intake. Positively framed practices such as these was also associated with increased consumption of vegetables and decreased consumption of sugar-sweetened beverages in a Norwegian study on 10-12-year-olds ${ }^{(71)}$. Mothers are of special interest because their food intake have been 
shown to be related to that of their children, presumably due to their role as 'gatekeepers' of food in the household ${ }^{(72)}$. Conforming to this, results from a study by Pinard, Yarosh, Hart et al. ${ }^{(73)}$, where home environmental contributors to obesity among children and adolescents aged 5 to 17 years were explored, indicated that mothers provide much of both the physical (availability/accessibility) and social (role modeling/policies/feeding styles) context in which child and adolescent food choices are made. Furthermore, the finding of perceived maternal HEG as a mediator of the relationship between family cohesion and adolescent vegetable consumption frequency is in line with the above-mentioned suggestions by Franko, Thompson, Bauserman, et al. ${ }^{(52)}$, as a high extent of family cohesion (as perceived by adolescents) may prepare the ground for effective maternal HEG. This could possibly reflect a mechanism where adolescents' perception and appreciation of a cohesive family environment makes them more open and responsive to maternal advice and guidance which, in turn, has a favorable effect on adolescent vegetable consumption. Hence, the findings from the present study sheds light on potential mechanisms involved in the dynamic relationships between different family environmental levels and adolescent eating behaviors.

No associations were found between adolescents' frequency of vegetable consumption and the parental level factors family dinner frequency and positive encouragement for vegetable consumption (PEV). The lack of association between vegetable consumption frequency and family dinner frequency may be explained by 1) the fact that in Norway, vegetables are mostly eaten at dinner ${ }^{(13)}$ and 2) the limited variation in family dinner frequency in the population of interest ${ }^{(14,15)}$ (the latter was confirmed in the present study). The lack of association seen for PEV could possibly be explained by a lack of parental encouragement specifically targeting vegetable consumption. Another possible explanation may be the adolescents' lack of recognition of such encouragement. The relatively low mean values for perceived maternal and paternal PEV in the present sample (see Table 2) support this line of reasoning. It is worth noting that the way children perceive getting support from their parents and the way parents perceive offering their support may be very different from each other ${ }^{(38)}$.

The lack of associations seen for the family level factors general family functioning and family conflict may be due to these factors' 'distance' to the behavior of interest as more proximal environmental (e.g. home availability/accessibility of vegetables), individual (e.g. taste preferences) and social (e.g. peer influence) factors may play a greater role in influencing adolescent dietary behaviors ${ }^{(74)}$. Nevertheless, both general family functioning 
and conflict may have an impact on the relationships between the more proximal factors and adolescent dietary behaviors, even if we were not able to detect it with the measures and analyses applied in the present study. For example, previous research has indicated that family conflict can significantly predict unhealthy dietary behaviors in adolescents ${ }^{(54,75)}$.

\section{Strengths and limitations}

There has been a call for research relating fundamental socioemotional family characteristics to adolescent eating ${ }^{(24)}$. Furthermore, research applying ecological models to increase the understanding of how processes within the family may influence adolescent dietary behaviors have been requested ${ }^{(76)}$. Thus, one strength of the present study is that it adds to the current literature by its ecological approach in assessing influences of the family environment on adolescent vegetable consumption, thereby acknowledging the dynamic interplay of various factors and levels of the home food environment. More specifically, this work combines wellresearched food parenting practices with less explored fundamental socioemotional family characteristics to uncover family environmental influences on adolescent vegetable consumption.

Among the limitations of the current work is the study's cross-sectional nature, which hampers causal inferences. The self-report on all study variables is another limitation, increasing the risk of social desirability responses and common methods bias. The application of a frequency measure for vegetable consumption may also be considered a limitation because of its limited accuracy regarding the amount of vegetables ingested. However, such accuracy was not a key issue in the present work where the intention was to rank individuals according to their usual consumption of vegetables in terms of frequency (i.e. times per week). The lower respondent burden of frequency measures compared to more accurate methods such as repeated 24-h recalls or food diaries, and their ability to capture long-term dietary intake ${ }^{(77)}$, were also reasons for choosing this approach. Frequency measures appear to be feasible instruments in survey research aiming at exploring associations between dietary habits and a wide range of potential determinants without wearing out the respondents. Also, the use of a convenience sample with a large proportion of adolescents from highly educated households may limit the generalizability of our findings. Moreover, the relatively low explanatory power of the multiple linear regression model may be considered a limitation. However, the objective of this study was not to adapt models with the greatest possible explanatory power, but to describe associations between adolescents' frequency of vegetable 
consumption, food parenting practices and socioemotional family characteristics - and to explore the potential processes involved.

\section{Conclusions}

The lower than recommended vegetable consumption in adolescents calls not only for studies and actions tailored directly towards this group of the population. Results from the present study suggest that perceived family cohesion may influence adolescent vegetable consumption both directly and indirectly (through maternal HEG), indicating that research and development of interventions directed towards the socioemotional aspects of the family environment may also be relevant. The large number of studies stating the importance of family meals suggests that developing interventions aimed at increasing the frequency of family meals could be a first step. Based on the findings from the current study, we suggest that a possible second step could be to provide parents with knowledge about how to create a socioemotional family environment that prepares the ground for positively framed food parenting practices and favorable eating behaviors. However, since knowledge is a prerequisite, but by itself not sufficient to induce behavior change, parent and adolescent empowerment and other underexplored factors and processes that may help explain adolescent eating behaviors in general, and vegetable consumption in particular, should also be included in future research. Ultimately, understanding the factors and mechanisms at play is essential for the development, implementation and success of any intervention. 


\section{References}

1. Lim SS, Vos T, Flaxman, AD et al. (2012) A comparative risk assessment of burden of disease and injury attributable to 67 risk factors and risk factor clusters in 21 regions, 1990-2010: a systematic analysis for the Global Burden of Disease Study 2010. Lancet 380, 2224-2260.

2. Fismen AS, Smith ORF, Torsheim T et al. (2016) Trends in food habits and their relation to socioeconomic status among Nordic adolescents 2001/2002-2009/2010. PLoS One 11, e0148541.

3. Vereecken C, Pedersen TP, Ojala K et al. (2015) Fruit and vegetable consumption trends among adolescents from 2002 to 2010 in 33 countries. Eur J Public Health 25, 16-19. 4. Golley RK, Hendrie GA \& McNaughton SA (2011) Scores on the dietary guideline index for children and adolescents are associated with nutrient intake and socio-economic position but not adiposity. J Nutr 141, 1340-1347.

5. Striegel-Moore RH \& Bulik CM (2007) Risk factors for eating disorders. Am Psychol 62, 181-198.

6. Lipsky LM, Haynie, DL \& Liu, D et al. Trajectories of eating behaviors in a nationally representative cohort of U.S. adolescents during the transition to young adulthood. Int $J$ Behav Nutr Phys Act. Published online: 4 November 2015. https://doi.org/10.1186/s12966015-0298-X.

7. Bere E, Hilsen M \& Klepp KI (2010) Effect of the nationwide free school fruit scheme in Norway. Brit J Nutr 104, 589-594.

8. Hovdenak IM, Bere E \& Stea TH. Time trends (1995-2008) in dietary habits among adolescents in relation to the Norwegian school fruit scheme: the HUNT study. Nutr J. Published online: 20 November 2019. https://doi.org/10.1186/s12937-019-0501-Z. 9. Øvrum A \& Bere E (2014) Evaluating free school fruit: results from a natural experiment in Norway with representative data. Public Health Nutr 17, 1224-1231. 10. Evans C, Christian M, Cleghorn C et al. (2012) Systematic review and meta-analysis of school-based interventions to improve daily fruit and vegetable intake in children aged 5 to 12 у. Am J Clin Nutr 96, 889-901.

11. Mäkelä J, Kjærnes U, Ekström MP et al. (1999) Nordic meals: methodological notes on a comparative survey. Appetite 32, 73-79.

12. Bere E, Veierød MB \& Klepp KI (2005) The Norwegian School Fruit Programme: evaluating paid vs. no-cost subscriptions. Prev Med 41, 463-470. 
13. Myhre JB, Løken EB, Wandel M et al. (2015) Meal types as sources for intakes of fruits, vegetables, fish and whole grains among Norwegian adults. Public Health Nutr 18, 2011-2021.

14. Hausken SE, Lie HC, Lien $\mathrm{N}$ et al. The reliability of the general functioning scale in Norwegian 13-15-year-old adolescents and association with family dinner frequency. Nutr $J$. Published online: 27 March 2019. https://doi.org/10.1186/s12937-019-0447-1.

15. Melbye EL, Øgaard T, Øverby NC et al. Parental food-related behaviors and family meal frequencies: associations in Norwegian dyads of parents and preadolescent children. BMC Public Health. Published online: 10 September 2013. https://doi.org/10.1186/14712458-13-820.

16. Berge JM (2009) A review of familial correlates of child and adolescent obesity: what has the 21 st century taught us so far? Int J Adolesc Med Health 21, 457-483.

17. Fulkerson JA, Larson N, Horning M et al. (2014) A review of associations between family or shared meal frequency and dietary and weight status outcomes across the lifespan. $J$ Nutr Educ Behav 46, 2-19.

18. Videon TM \& Manning CK (2003) Influences on adolescent eating patterns: the importance of family meals. J Adolesc Health 32, 365-373.

19. Totland TH, Knudsen MD, Paulsen MM et al. Correlates of irregular family meal patterns among 11-year-old children from the Pro Children study. Food Nutr Res. Published online: 22 June 2017. https://doi.org/10.1080/16546628.2017.1339554.

20. Pearson N, Atkin AJ, Biddle SJ et al. (2010) Parenting styles, family structure and adolescent dietary behaviour. Public Health Nutr 13, 1245-1253.

21. Gebremariam MK, Henjum S, Terragni L et al. Correlates of fruit, vegetable, soft drink, and snack intake among adolescents: the ESSENS study. Food Nutr Res. Published online: 20 Sep 2016. https://doi.org/10.3402/fnr.v60.32512.

22. Gebremariam MK, Lien N, Torheim LE et al. Perceived rules and accessibility: measurement and mediating role in the association between parental education and vegetable and soft drink intake. Nutr J. Published online: 17 August 2016.

https://doi.org/10.1186/s12937-016-0196-3.

23. Pearson N, Biddle SJ \& Gorely T (2009) Family correlates of breakfast consumption among children and adolescents. A systematic review. Appetite 52, 1-7.

24. Larson N, MacLehose R, Fulkerson JA et al. (2013) Eating breakfast and dinner together as a family: associations with sociodemographic characteristics and implications for diet quality and weight status. J Acad Nutr Dietet 113, 1601-1609. 
25. Balistreri KS \& Alvira-Hammond M (2016) Adverse childhood experiences, family functioning and adolescent health and emotional well-being. Public Health 132, 72-78.

26. Brown SL (2006) Family structure transitions and adolescent well-being. Demography 43, 447-461.

27. Shek DT (2002) Family functioning and psychological well-being, school adjustment, and problem behavior in Chinese adolescents with and without economic disadvantage. $J$ Genet Psychol 163, 497-502.

28. Kitzmann KM \& Beech BM (2006) Family-based interventions for pediatric obesity: Methodological and conceptual challenges from family psychology. J Fam Psychol 20, 175189.

29. Sleddens EF, Gerards SM, Thijs C et al. (2011) General parenting, childhood overweight and obesity-inducing behaviors: A review. Int J Pediatr Obes 6, e12-e27.

30. Bjelland M, Hausken SE, Sleddens EF et al. Development of family and dietary habits questionnaires: the assessment of family processes, dietary habits and adolescents' impulsiveness in Norwegian adolescents and their parents. Int J Behav Nutr Phys Act. Published online: 15 October 2014. https://doi.org/10.1186/s12966-014-0130-z. 31. Lien N, Bjelland M, Bergh IH et al. (2010). Design of a 20-month comprehensive, multicomponent school-based randomised trial to promote healthy weight development among 11-13 year olds: The HEalth In Adolescents study. Scand J Public Health 38, 38-51. 32. Andersen L, Bere E, Kolbjornsen N et al. (2004). Validity and reproducibility of selfreported intake of fruit and vegetable among 6th graders. Eur J Clin Nutr 58, 771-777.

33. Bere $\mathrm{E} \&$ Klepp K Changes in accessibility and preferences predict children's future fruit and vegetable intake. Int J Behav Nutr Phys Act. Published online: 10 October 2005. https://doi.org/10.1186/1479-5868-2-15.

34. Melbye EL, Øverby NC \& Øgaard T (2012) Child consumption of fruit and vegetables: the roles of child cognitions and parental feeding practices. Public Health Nutr 15, 1047-1055.

35. Haszard JJ, Williams SM, Dawson AM et al. (2013) Factor analysis of the Comprehensive Feeding Practices Questionnaire in a large sample of children. Appetite 62, 110-118.

36. Musher-Eizenman D \& Holub S (2007) Comprehensive feeding practices questionnaire: validation of a new measure of parental feeding practices. J Pediatr Psychol 32, 960-972. 
37. Melbye EL, Øgaard T \& Øverby NC. Validation of the comprehensive feeding practices questionnaire with parents of 10-to-12-year-olds. BMC Med Res Methodol. Published online: 09 August 2011. https://doi.org/10.1186/1471-2288-11-113.

38. Dave JM, Evans AE, Condrasky MD et al. (2012) Parent-reported Social Support for Child's Fruit and Vegetable Intake: Validity of Measures. J Nutr Edu Behav 44, 132-139. 39. Melbye EL, Øgaard T \& Øverby NC (2013) Associations between parental feeding practices and child vegetable consumption: Mediation by child cognitions? Appetite 69, 2330.

40. Young EM, Fors SW \& Hayes DM (2004) Associations between Perceived Parent Behaviors and Middle School Student Fruit and Vegetable Consumption. J Nutr Edu Behav 36, 2-12.

41. Bowen M (1978) Family therapy in clinical practice. New York: Jason Aronson, Inc. 42. Epstein NB, Baldwin LM \& Bishop DS (1983) The McMaster family assessment device. J Marital Fam Ther 9, 171-180.

43. Byles J, Byrne C, Boyle MH et al. (1988) Ontario Child Health Study: reliability and validity of the general functioning subscale of the McMaster Family Assessment Device. Fam Process 27, 97-104.

44. Ridenour TA, Daley J \& Reich W (1999) Factor analyses of the family assessment device. Fam Process 38, 497-510.

45. Kazarian SS (2010) Cultural appropriateness of the Family Assessment Device (FAD) in the case of ethnic Armenian adolescents in Lebanon. Int J Soc Psychiatry 56, 230-238. 46. Pedersen MA, Kristensen LJ, Sildorf SM et al. (2019) Assessment of family functioning in families with a child diagnosed with type 1 diabetes: validation and clinical relevance of the general functioning subscale of the McMaster family assessment device. Pediatr Diabetes 20, 785-793.

47. Shek DT (2001) The general functioning scale of the Family Assessment Device: does it work with Chinese adolescents? J Clin Psychol 57, 1503-1516.

48. Moos RH \& Moos BS (1987) Family Environment Scale. In Handbook of Measurements for Marriage and Family Therapy, pp. 82-86 [Fredman N \& R Sherman, editors]. New York: Brunner/Mazel Inc.

49. Ackard DM, Neumark-Sztainer D, Story M et al. (2006) Parent - child connectedness and behavioral and emotional health among adolescents. Am J Prev Med 30, 59-66.

50. Franko DL, Thompson D, Affenito SG et al. (2008) What mediates the relationship between family meals and adolescent health issues. Health Psycholol 27, 109-117. 
51. Zdanowicz N, Janne P \& Reynaert C (2004) Family, health, and adolescence. Psychosomatics 45, 500-507.

52. Franko DL, Thompson D, Bauserman R et al. (2008) What's love got to do with it? Family cohesion and healthy eating behaviors in adolescent girls. Int J Eat Disord 41, 360367.

53. Haerens L, Craeynest M, Deforche B et al. (2008) The contribution of psychosocial and home environmental factors in explaining eating behaviours in adolescents. Eur J Clin Nutr 62, 51-59.

54. Kalavana TV, Maes S \& De Gucht V (2010) Interpersonal and self-regulation determinants of healthy and unhealthy eating behavior in adolescents. J Health Psychol 15, 44-52.

55. Moos RH (1990) Conceptual and empirical approaches to developing family-based assessment procedures: Resolving the case of the Family Environment Scale. Fam Process 29, 199-208.

56. Repetti RL, Taylor SE \& Seeman TE (2002) Risky families: family social environments and the mental and physical health of offspring. Psychol Bull 128, 330-366. 57. Ross RD, Marrinan S, Schattner S et al. (1999) The relationship between perceived family environment and psychological wellbeing: Mother, father, and adolescent reports. Aust Psychol 34, 58-63.

58. Wadsworth ME \& Compas BE (2002) Coping with family conflict and economic strain: The adolescent perspective. J Res Adolesc 12, 243-274.

59. Schuetzmann M, Richter-Appelt H, Schulte-Markwort M et al. (2008) Associations among the perceived parent-child relationship, eating behavior, and body weight in preadolescents: results from a community-based sample. J Pediatr Psychol 33, 772-782.

60. Charalampous K, Kokkinos CM \& Panayiotou G (2013) The Family Environment Scale: Resolving psychometric problems through an examination of a Greek translation. Int $J$ Edu Psychol Assess 13, 81-99.

61. Xu Y, Boyd RC, Butler L et al. (2017) Associations of parent-adolescent discrepancies in family cohesion and conflict with adolescent impairment. J Child Fam Stud 26, 3360-3369.

62. Kline RB (2005) Methodology in the social sciences. Principles and practice of structural equation modeling, 2nd ed. New York: Guilford Press.

63. Field A (2013) Discovering statistics using IBM SPSS statistics, 4th ed. London: Sage publications Ltd. 
64. Singh AS, Vik FN, Chinapaw MJ et al. Test-retest reliability and construct validity of the ENERGY-child questionnaire on energy balance-related behaviours and their potential determinants: the ENERGY-project. Int J Behav Nutr Phys Act. Published online: 09 December 2011. https://doi.org/10.1186/1479-5868-8-136.

65. Hayes AF (2017) Introduction to mediation, moderation, and conditional process analysis: A regression-based approach, 2nd ed. New York: Guilford Press.

66. Cerin E \& MacKinnon DP (2009) A commentary on current practice in mediating variable analyses in behavioural nutrition and physical activity. Public Health Nutr 12, 11821188.

67. Fritz MS, Taylor AB \& Mackinnon DP (2012) Explanation of Two Anomalous Results in Statistical Mediation Analysis. Multivar Behav Res 47, 61-87.

68. Gelfand LA, Mensinger JL \& Tenhave T (2009) Mediation analysis: A retrospective snapshot of practice and more recent directions. J Gen Psychol 136, 153-178.

69. Moore J \& Harré N (2007) Eating and activity: the importance of family and environment. Health Promot J Aust 18, 143-148.

70. Couch SC, Glanz K, Zhou C et al. (2014) Home food environment in relation to children's diet quality and weight status. J Acad Nutr Dietet 114, 1569-1579.

71. Melbye EL \& Hansen H Promotion and prevention focused feeding strategies: exploring the effects on healthy and unhealthy child eating. BioMed Res Int. Published online: 25 Aug 2015. https://doi.org/10.1155/2015/306306.

72. Campbell K \& Crawford D (2007) Associations between the home food environment and obesity-promoting eating behaviors in adolescence. Obesity 15, 719-730.

73. Pinard CA, Yaroch AL, Hart MH et al. (2014) The validity and reliability of the Comprehensive Home Environment Survey (CHES). Health Promot Pract 15, 109-117. 74. Berge JM, Wall M, Larson N et al. (2013) Family functioning: associations with weight status, eating behaviors, and physical activity in adolescents. J Adolesc Health 52, 351-357.

75. Byely L, Archibald AB, Graber J et al. (2000) A prospective study of familial and social influences on girls' body image and dieting. Int J Eat Disord 28,155-164.

76. Patrick H, Hennessy E, McSpadden K et al. (2013) Parenting styles and practices in children's obesogenic behaviors: scientific gaps and future research directions. Child Obes $\mathbf{9}$, 73-86.

77. Cade J, Thompson R, Burley V et al. (2002) Development, validation and utilisation of food-frequency questionnaires - a review. Public Health Nutr 5, 567-587. 


\section{Accepted manuscript}

Table 1. Frequencies for categorical variables $(n=440)$.

\begin{tabular}{lc}
\hline Variable & $\%$ \\
\hline Adolescent gender & 52 \\
Female & 48 \\
Male & \\
Household educational level & 34 \\
$\leq 12$ years & 39 \\
$13-16$ years & 27 \\
$>16$ years & \\
Family structure & 69 \\
Living with both parents & 31 \\
Other living arrangements & \\
Family dinner frequency & 19 \\
$0-5$ times/week & 81 \\
6-7 times/week & \\
\hline
\end{tabular}


Table 2. Means, standard deviations (SD), skewness, kurtosis, Cronbach's alphas $(\alpha)$ and intraclass correlations (ICC) for rating scale variables.

\begin{tabular}{lllllll}
\hline Variable/scale (number of items) & Mean $^{\mathbf{a}}$ & SD $^{\mathbf{a}}$ & Skewness $^{\mathbf{a}}$ & Kurtosis $^{\mathbf{a}}$ & $\mathbf{a}^{\mathbf{a}}$ & ICC $^{\mathbf{b}}$ \\
\hline Adolescent vegetable consumption $^{\mathbf{c}}$ (2) & 9.46 & 6.37 & 1.36 & 2.47 & - & 0.69 \\
Family functioning (12) & 1.72 & 0.46 & 0.56 & 0.36 & 0.85 & 0.83 \\
Family cohesion (9) & 3.37 & 0.45 & -0.88 & 0.54 & 0.83 & 0.82 \\
Family conflict (8) & 1.89 & 0.50 & 0.45 & -0.11 & 0.72 & 0.73 \\
HEG, mothers (9) & 2.16 & 0.83 & -0.81 & 0.39 & 0.87 & 0.71 \\
HEG, fathers (9) & 2.31 & 0.88 & -0.68 & 0.09 & 0.89 & 0.68 \\
PEV, mothers (5) & 2.41 & 0.98 & 0.24 & -0.63 & 0.87 & 0.72 \\
PEV, fathers (5) & 2.24 & 0.98 & 0.45 & -0.45 & 0.88 & 0.68 \\
\hline
\end{tabular}

HEG, healthy eating guidance; PEV, positive encouragement for vegetable consumption.

${ }^{\mathrm{a}} \mathrm{n}=440,{ }^{\mathrm{b}} \mathrm{n}=54,{ }^{\mathrm{c}}$ times/week 
Table 3. Regression coefficients $(\beta)$ and variance explained $\left(R^{2}\right)$ for multiple linear regression on vegetable consumption frequency.

\begin{tabular}{lc}
\hline Independent variables & $\boldsymbol{\beta}$ \\
\hline Sociodemographic factors (covariates) & -0.03 \\
Adolescent gender & $0.11^{*}$ \\
Household educational level & -0.04 \\
Family structure & \\
Socioemotional family characteristics & -0.14 \\
Family functioning & $0.21^{*}$ \\
Family cohesion & -0.07 \\
Family conflict & \\
Sociocultural factors & 0.07 \\
Family dinner frequency & $0.22^{*}$ \\
HEG, mothers & -0.11 \\
HEG, fathers & 0.00 \\
PEV, mothers & 0.00 \\
PEV, fathers & 0.09 \\
$R^{2}$ & \\
\hline
\end{tabular}

HEG, healthy eating guidance; PEV, positive encouragement for vegetable consumption.

$* \mathrm{p}<0.05$ 
Figure 1. Path diagram for modeling family cohesion as a predictor of adolescents' frequency of vegetable consumption, partly mediated by maternal healthy eating guidance (HEG). Coefficient estimates (b) and statistical significance tests (p-values and CI) were obtained using the PROCESS script for SPSS.

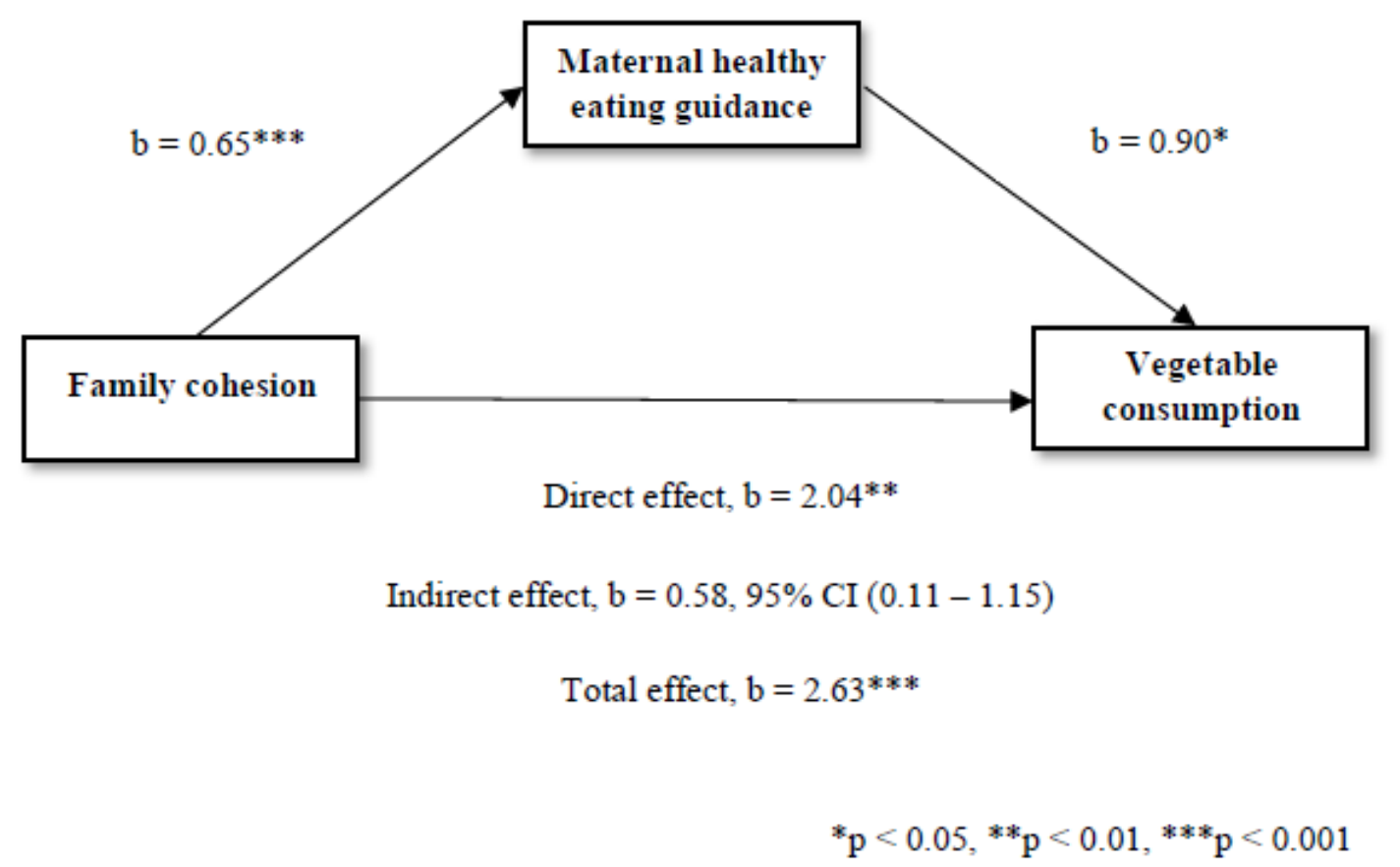

